Article

\title{
Characterization of Phytochemicals in Berry Fruit Wines Analyzed by Liquid Chromatography Coupled to Photodiode-Array Detection and Electrospray Ionization/Ion Trap Mass Spectrometry (LC-DAD-ESI-MS ${ }^{n}$ ) and Their Antioxidant and Antimicrobial Activity
}

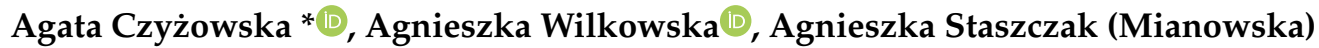 \\ and Agnieszka Nowak (D) \\ Institute of Fermentation Technology and Microbiology, Faculty of Biotechnology and Food Sciences, \\ Lodz University of Technology, 171/173 Wolczanska Street, 90-924 Lodz, Poland; \\ agnieszka.wilkowska@p.lodz.pl (A.W.); agnieszkamianowska@op.pl (A.S.); agnieszka.nowak@p.lodz.pl (A.N.) \\ * Correspondence: agata.czyzowska@p.lodz.pl
}

Received: 29 September 2020; Accepted: 26 November 2020; Published: 1 December 2020

\begin{abstract}
Fruits are a valuable source of phytochemicals. However, there is little detailed information about the compounds contained in fruit wines. In this study, wines from six different berries were analyzed using HPLC-DAD-ESI-MS ${ }^{n}$. About 150 compounds were identified, including anthocyanins (34), hydroxycinnamic acids (12) and flavonols (36). Some of the compounds were identified for the first time in berry wines. The blackberry wines were found to contain the largest number of bioactive compounds (59). Elderberry wines where the richest source of polyphenols (over $1000 \mathrm{mg} / \mathrm{L}$ ) and contained the largest amounts of all of the analyzed groups of compounds (hydroxycinnamic acids, anthocyanins and flavonols). The lowest concentration of polyphenols was observed in the wines made from cranberries and bilberries (less than $500 \mathrm{mg} / \mathrm{L}$ ). The antioxidant activity was determined in relation to $\mathrm{ABTS}^{+}$, DPPH, and FRAP. The highest values were observed in the blackberry wines, and the lowest for the cranberry wines. The wines were analyzed to test their antimicrobial activity. Five of the six wines (with the exception of elderberry wine) inhibited Bacillus cereus growth and two (blackberry and cranberry wines) were active against Listeria monocytogenes.
\end{abstract}

Keywords: berries; fruit wines polyphenols identification; LC-MS ${ }^{n}$

\section{Introduction}

Fruits are known to be a valuable source of phytochemicals. However, there is little detailed information in the literature about the compounds contained in fruit wines [1-9]. Only fruit wines from strawberries and bilberries (Vaccinium myrtillus L.) have been studied intensively [10-12]. Behrend and Weber [10] analyzed the anthocyanins and tannins in bilberry wines fermented after different pretreatments and during ageing. Liquid chromatography-mass spectrometry (LC-MS) of the anthocyanins was performed using an LTQ-XL ion trap mass spectrometer connected to a UHPLC system via an electrospray ionization (ESI) interface. The anthocyanin profiles of all the wines were identical at the start of fermentation. During fermentation, considerable changes were noticed. The wines that had been subjected to prefermentative thermal treatment had an almost juice-like composition. The other wines displayed lower levels of arabinosides and galactosides. Polymeric pigments and pyranoanthocyanins were observed in all the wines. Liu et al. [12] analyzed bilberry wines 
by liquid chromatography using a diode array detector and electrospray ionization-quadrapole/time of flight hybrid mass spectrometry (ESI-QTOF-MS). They identified 42 nonanthocyanin compounds, including 22 phenolic acids, 15 flavonols and 5 flavan-3-ols. Hornedo-Ortega et al. [11] analyzed the anthocyanins in strawberry beverages. The anthocyanin fraction of the fermented strawberry wine was analyzed on an Amberlite XAD7HP column. Four anthocyanin compounds were identified with high accuracy for the first time in strawberry wines: pelargonidin-3-sambubioside, pelargonidin disaccharide (hexose + pentose) acylated with acetic acid, cyanidin-3-(6-acetyl)-glucoside, and pelargonidin 3-(6-succinyl)-arabinoside/3-(6-malonyl)-rhamnoside.

Papadopoulou et al. [13] demonstrated the antibacterial activity of the polyphenols in various white and red wines against strains of Staphylococcus aureus and Escherichia coli. Fruit wines, which are also a rich source of polyphenolic compounds and other bioactive compounds [2-9], may have similar antibacterial properties.

Polyphenols can also show antifungal activity, although it is much weaker [13,14]. Moreover, via various mechanisms, polyphenolic compounds limit the acquisition of resistance by microorganisms [15].

Red and purple fruits are rich sources of anthocyanins, which show bacteriostatic and bactericidal activity against many microorganisms (including Staphylococcus sp., Klebsiella sp., Helicobacter and Bacillus) $[16,17]$. Raspberries and cloudberries are rich sources of ellagitannins. These compounds are also found in strawberries, but in smaller amounts $[17,18]$. Quercetin is another compound found in fruits. It has been shown to increase the permeability of bacterial cell wall, which may, for example, increase the sensitivity of bacteria to antibiotics [19]. In many cases, mixtures of these compounds have been found to have stronger effects than any of their components separately. Of the various berries, raspberries and cloudberries (Rubus chamaemorus) are recognized as the best inhibitors of bacteria such as Staphylococcus spp., Salmonella spp., Helicobacter pylori and Bacillus cereus [20,21]. Raspberry juice has been reported to completely inhibit the growth of Escherichia coli in vitro [22].

Berries are also a rich source of vitamins A, C, and E. Ascorbic acid is found in a wide variety of fresh fruits [23]. In addition to having redox potential, it is also an excellent electron donor in biological systems [24]. Epidemiological and experimental evidence suggests that vitamin $C$ can protect against the development of gastric cancer by several potential mechanisms: it reduces gastric mucosal oxidative stress, DNA damage, and gastric inflammation by scavenging ROS (reactive oxygen species); it inhibits gastric nitrosation and the formation of $\mathrm{N}$-nitroso compounds by reducing nitrous acid to nitric oxide and producing dehydroascorbic acid in the stomach; it enhances host immunologic functions; it has a direct effect on Helicobacter pylori growth and virulence; it inhibits gastric cell proliferation and induces apoptosis [25]. The content of vitamin $C$ in berry fruits can be influenced by numerous factors, including the species, variety, weather conditions, ripeness, and region [23]. Vitamin stability can be affected by various technological practices used during the processing of food, namely changes in temperature (e.g., thermal treatments) and oxygen levels [24]. The concentration of vitamins decreases during winemaking (fermentation and ageing) [26].

In this study, we characterize and quantify the bioactive compounds in wines made from six different berries, using HPLC-DAD-ESI-MS ${ }^{n}$. We also investigate whether the fruit wines may be considered a source of antimicrobial agents against pathogenic microorganisms. The fruit wines were tested against both pathogenic Gram-negative bacteria (E. coli and Salmonella Enteritidis), which can cause foodborne and waterborne outbreaks of gastrointestinal tract infections, and pathogenic Gram-positive bacteria (B. cereus, L. monocytogenes and S. aureus), which can cause food poisoning and toxic symptoms in humans. Candida albicans ATCC 10231, was used as a reference strain for the analysis of antifungal action [27]. Some of these microbes can also colonize oral human cavities [28-32]. Studies suggest that between $94 \%$ and $100 \%$ of healthy adults have oral colonization with Staphylococcus spp. [30] and oral carriage of S. aureus ranges from $24 \%$ to $36 \%$ [31]. 


\section{Materials and Methods}

\subsection{Reagents and Standards}

ABTS $^{+\bullet}\left(2,2^{\prime}\right.$-azinobis 3-ethylbenzothiazoline-6-sulfonic acid), potassium persulphate, $\mathrm{FeCl}_{3}$, TPTZ (2,4,6-Tris (2-pyridyl-S-triazine), $\mathrm{DPPH}^{+\bullet}$ (2,2-diphenyl-1-picrylhydrazyl) and methanol were purchased from Sigma (Poznań, Poland). Formic acid and HPLC-grade acetonitrile were sourced from J.T. Baker (Witko, Poland). Anthocyanin standards were produced by Extrasynthese (Genay, France) and PhytoLab (Vestenbergsgreuth, Germany). Available standards of other polyphenols were purchased from Sigma (Poznań, Poland) and Extrasynthese (Genay, France). HPLC-grade water was obtained using an Aquinity E60 Lifescience TI system (membraPure GmbH, Bodenheim, Germany).

\subsection{Wine Preparation}

Fruit wines were prepared according to the Polish Law of 12 May 2011 'On the production and bottling of wine products, trade and organization of the wine market'. Six wine types were made from the following berries: bilberry (common bilberry) (Vaccinium myrtillus L.) —BB; blackberry (Rubus L.) -B; cranberry (Vaccinium macrocarpon Aiton)—C; elderberry (Sambucus nigra L.)—E; raspberry (Rubus idaeus L.) - R; and strawberry (Fragaria $\times$ ananassa) - S (Kent variety).

Fresh blackberry, cranberry, raspberry and strawberry fruits (about $10 \mathrm{~kg}$ of each species) were purchased from local retailers between June and October, depending on the availability. Bilberry fruits were collected in the region of Belchatow $\left(51^{\circ} 21^{\prime} \mathrm{N}, 19^{\circ} 21^{\prime} \mathrm{E}\right)$ and elderberry fruits in Pabianice $\left(51^{\circ} 39^{\prime} \mathrm{N}, 19^{\circ} 21^{\prime} \mathrm{E}\right)$. The elderberry stalks were removed. The fruits were then heat treated $\left(85^{\circ} \mathrm{C}\right.$, $5 \mathrm{~min}$ ) to inactivate polyphenol oxidase-type enzymes. The blueberry, elderberry and cranberry pulps were cooled to $50{ }^{\circ} \mathrm{C}$ and treated with pectinolytic enzyme (Rohapect $10 \mathrm{~L}$, AB Enzymes GmbH, Darmstadt Germany, AKE, Pabianice, Poland) at a dose of $0.5 \mathrm{~g} / \mathrm{kg}$ of fruits. They were then pressed using a hydraulic press.

Fermentation was performed at $25^{\circ} \mathrm{C}$ using BCS103 wine yeast (Fermentis, LeMag, Żyrardów, Poland) at a dose of $0.2 \mathrm{~g} / \mathrm{L}$. Once fermentation was complete, the wine was racked and poured into bottles. All the wines were aged for around 5 months. The wines were then subjected to basic analysis (alcohol, extract, sugar, acidity). The wines were dealcoholated and tested for their antimicrobial activity.

\subsection{Preparation of Dealcoholated Red Wines (DRW)}

To remove the alcohol from the wines, an equal volume of distilled water was added to a given volume of wine and then concentrated to the original volume ( $38 \mathrm{mbar}, 35^{\circ} \mathrm{C}, 140-180 \mathrm{rev} / \mathrm{min}$ ). The solutions were concentrated on a Büchi vacuum evaporator-Rotavapor R-215 (Büchi Labortechnik AG, Flawil, Switzerland).

\subsection{Analysis of Organic Acids, Sugars and Alcohols}

Organic acids, glucose, fructose and alcohols (ethanol and glycerol) were analyzed using a Finnigan Surveyor HPLC system (Thermo Fisher Scientific Inc., Waltham, MA, USA), according to the method described by Czyżowska et al. [33].

\subsection{Total Phenolic Content (TPC) Assay}

Total phenolic content (TPC) was determined using the Folin-Ciocalteu reaction with gallic acid as a standard. To a test tube were added $0.1 \mathrm{~mL}$ of the 5 -fold diluted sample, $0.2 \mathrm{~mL}$ of Folin-Ciocalteu reagent, $1 \mathrm{~mL}$ of $20 \%$ sodium carbonate and $2 \mathrm{~mL}$ of distilled water. In the control, $0.1 \mathrm{~mL}$ of distilled water was added instead of the test solution. The samples were mixed and incubated for $1 \mathrm{~h}$ at room temperature, in the absence of light. After incubation, the absorbance was measured at a wavelength of $\lambda=765$ nm (Cecil CE 2041, Cecil Instruments Limited, Cambridge, UK). 


\subsection{Analysis of Antioxidant Capacity}

\subsubsection{ABTS Radical-Scavenging System}

Radical scavenging activity against $\mathrm{ABTS}^{+\bullet}$ was determined based on the method described by Rivero-Pérez et al. [34] with slight modifications. The wine solution $(0.2 \mathrm{~mL})$ was mixed with $4 \mathrm{~mL}$ of ABTS reagent and incubated for $15 \mathrm{~min}$. The results were expressed as $\mathrm{mM}$ of Trolox equivalents, using linear calibration obtained with different concentrations of Trolox.

\subsubsection{DPPH Radical-Scavenging System}

The method described by Fogliano et al. [35] was applied with slight modifications. Wine solution $(0.2 \mathrm{~mL})$ was mixed with $4 \mathrm{~mL}$ of $\mathrm{DPPH}^{+\bullet}$ reagent $(65 \mu \mathrm{M})$ and incubated for $30 \mathrm{~min}$. Absorbance was measured at $515 \mathrm{~nm}$. The results were expressed as $\mathrm{mM}$ of Trolox equivalents on the relevant calibration curve.

\subsubsection{FRAP Method}

The method described by Rivero-Pérez et al. [34] was used with slight modifications. For $30 \mathrm{~min}$, $2.9 \mathrm{~mL}$ of the reactive mixture was incubated with $50 \mu \mathrm{L}$ of the sample. Absorbance was measured at $595 \mathrm{~nm}$. The results were expressed as $\mathrm{mM}$ of Trolox equivalents on the relevant calibration curve.

\subsection{LC-MS $S^{n}$ Identification of Wines Compounds}

Qualitative analysis of the bioactive compounds in the berry wines was conducted using an HPLC coupled on-line with an MS LTQ Velos mass spectrometer (ThermoScientific, Waltham, MA, USA), following the method described by Efenberger-Szmechtyk et al. [36]. Separation was carried out using a Hypersil Gold column $(150 \times 2.1$, particle size $1.9 \mu \mathrm{m})$ (ThermoScientific, Waltham, MA, USA). The column was thermostated at $45^{\circ} \mathrm{C}$. For the anthocyanins, $2.5 \%$ formic acid solution (phase A) and $95 \%$ acetonitrile (phase B) were used as eluents with a flow rate of $220 \mu \mathrm{L} / \mathrm{min}$ and an injection volume of $10 \mu \mathrm{L}$. For other compounds, the mobile phase consisted of solvent $\mathrm{A}(1 \mathrm{~mL}$ formic acid in $1 \mathrm{~L}$ of deionized water) and solvent B (95\% acetonitryl). The separation was carried out with the following gradients: in the first $8 \mathrm{~min}$, a linear gradient from $96 \%$ to $85 \%$ phase A; 8-12 min linear gradient from $85 \%$ to $82 \%$ phase $\mathrm{A} ; 12-40$ min linear gradient from $82 \%$ to $60 \%$ phase $\mathrm{A} ; 40-44$ min linear gradient from $60 \%$ to $50 \%$ phase $A ; 44-47$ min linear gradient from $60 \%$ to $50 \%$ phase $A ; 47-49$ min linear gradient from $50 \%$ to $96 \%$ phase A, followed by column recalibration.

Spectrometry was performed with a capillary voltage of $4 \mathrm{kV}$ and collision energy of $20 \mathrm{~V}$. The desolvation temperature was $280^{\circ} \mathrm{C}$ and the source temperature was $350{ }^{\circ} \mathrm{C}$.

Detection of anthocyanins was carried out in positive ion mode, whereas the other compounds were detected in the negative ion mode in the range of $\mathrm{m} / \mathrm{z}$ from 100 to 1200 . The compounds were identified based on a comparison of the maximum absorption spectra of $U V$ radiation. The molecular weight was determined on the basis of the mass to charge ratio. Retention times and fragmentation spectra were compared with the available standards and literature data.

\subsection{HPLC Analysis of Polyphenols}

Prior to analysis, the samples were filtered through a $0.45 \mu \mathrm{m}$ membrane and injected into the HPLC system. HPLC-PDA analyses were performed using a Finnigan Surveyor equipped with an autosampler, a diode array detector Finnigan Surveyor-PDA Plus (Thermo FisherScientific Inc., Waltham, MA, USA) and ChromQuest 5.0 chromatography software (Thermo FisherScientific Inc., Waltham, MA, USA). The separation conditions were as described by Efenberger-Szmechtyk et al. [36]. The calibration curves were established using standards for chlorogenic acid, quercetin-glucoside and cyanidin-glucoside to quantify polyphenols at 320, 360 and $520 \mathrm{~nm}$, respectively. 


\subsection{Analysis of Antimicrobial Activity in Dealcoholated Red Wines (DRW)}

The biological materials used for the antimicrobial tests were strains of bacteria and yeasts: Bacillus cereus ŁOCK 0807, Escherichia coli ATTC 10536, Listeria monocytogenes ATTC 13932, Salmonella Enteritidis ATTC 13076, Staphylococcus aureus ATCC 6538 and Candida albicans ATCC 10231.

Antimicrobial Assay

The agar well diffusion method was used to verify whether the DRW affected the growth of the microorganisms [9]. A TSB (Trypticase soy broth) medium was used to activate cultures of bacteria following storage in the CRYOBANK ${ }^{\mathrm{TM}}$ system and YPD (Yeast Extract-Peptone-Dextrose) medium was used to activate the yeasts. After $24 \mathrm{~h}$, the cultures were submitted for further analysis. Standardized inocula of the tested microorganisms were incubated in TSA (Trypticase soy agar) or YPD, depending on the groups of microorganisms. Next, wells with a diameter of 9 mm were punched aseptically with a sterile cork borer. To each well was added $120 \mu \mathrm{L}$ of DRW. The samples were incubated at $37{ }^{\circ} \mathrm{C}$ for bacteria and $30{ }^{\circ} \mathrm{C}$ for yeast. After incubation, the inhibition zones were measured.

\subsection{Statistical Analysis}

Mean values, standard deviations and the occurrence of statistically significant differences were determined using STATISTICA 10 PL software (StatSoft, Krakow, Poland). The ANOVA test was used, assuming a significance level of 0.05 .

\section{Results and Discussion}

\subsection{Sugars, Organic Acids and Alcohols}

The alcohol content of the wines ranged from $7.22 \%$ to $14.59 \%(v / v$, Table 1$)$. The lowest alcohol content was detected in the cranberry wines and the highest in the elderberry wines. The wines with the highest alcohol contents had low or trace amounts of glucose.

Table 1. Organic acids, sugars, glycerol $(\mathrm{g} / \mathrm{L})$ and ethanol ( $v / v$ in the investigated wines).

\begin{tabular}{ccccccc}
\hline & BB & B & C & E & R & S \\
\hline citric acid & $1.17 \pm 0.15^{\mathrm{a}}$ & $4.53 \pm 0.35^{\mathrm{d}}$ & $1.95 \pm 0.09^{\mathrm{b}}$ & $2.45 \pm 0.08^{\mathrm{c}}$ & $8.74 \pm 0.65^{\mathrm{f}}$ & $5.03 \pm 0.15^{\mathrm{e}}$ \\
malic acid & $0.65 \pm 0.05^{\mathrm{b}}$ & $2.03 \pm 0.09^{\mathrm{f}}$ & $1.63 \pm 0.07^{\mathrm{e}}$ & $1.15 \pm 0.06^{\mathrm{d}}$ & $0.44 \pm 0.02^{\mathrm{a}}$ & $0.95 \pm 0.03^{\mathrm{c}}$ \\
succinic acid & $0.71 \pm 0.05^{\mathrm{b}}$ & $0.99 \pm 0.08^{\mathrm{c}}$ & $0.76 \pm 0.05^{\mathrm{b}}$ & $0.92 \pm 0.06^{\mathrm{c}}$ & $0.62 \pm 0.03^{\mathrm{a}}$ & $0.56 \pm 0.03^{\mathrm{a}}$ \\
lactic acid & $0.28 \pm 0.02^{\mathrm{b}}$ & $0.02 \pm 0.00^{\mathrm{a}}$ & $0.02 \pm 0.00^{\mathrm{a}}$ & $0.54 \pm 0.02^{\mathrm{c}}$ & $0.02 \pm 0.00^{\mathrm{a}}$ & $0.02 \pm 0.00^{\mathrm{a}}$ \\
acetic acid & $0.50 \pm 0.03^{\mathrm{c}}$ & $0.24 \pm 0.02^{\mathrm{b}}$ & $0.09 \pm 0.01^{\mathrm{a}}$ & uLOQ & uLOQ & uLOQ \\
ascorbic acid & $0.08 \pm 0.01^{\mathrm{c}}$ & $0.04 \pm 0.00^{\mathrm{b}}$ & $0.03 \pm 0.00^{\mathrm{a}}$ & uLOQ & $0.07 \pm 0.00^{\mathrm{c}}$ & uLOQ \\
glucose & $\mathrm{uLOQ}$ & $\mathrm{uLOQ}$ & $43.43 \pm 2.01^{\mathrm{c}}$ & $0.04 \pm 0.00^{\mathrm{a}}$ & $0.10 \pm 0.01^{\mathrm{b}}$ & uLOQ \\
fructose & $0.47 \pm 0.03^{\mathrm{a}}$ & $0.68 \pm 0.05^{\mathrm{b}}$ & $29.06 \pm 1.98^{\mathrm{e}}$ & $0.67 \pm 0.05^{\mathrm{b}}$ & $0.85 \pm 0.06^{\mathrm{c}}$ & $1.62 \pm 0.08^{\mathrm{d}}$ \\
glycerol & $8.58 \pm 0.65^{\mathrm{c}}$ & $10.81 \pm 0.77^{\mathrm{d}}$ & $4.95 \pm 0.32^{\mathrm{a}}$ & $8.03 \pm 0.63^{\mathrm{bc}}$ & $5.41 \pm 0.35^{\mathrm{a}}$ & $6.96 \pm 0.54^{\mathrm{b}}$ \\
ethanol & $12.86 \pm 1.01^{\mathrm{c}}$ & $14.39 \pm 1.06^{\mathrm{d}}$ & $7.22 \pm 0.56^{\mathrm{a}}$ & $14.59 \pm 0.99^{\mathrm{d}}$ & $8.43 \pm 0.65^{\mathrm{b}}$ & $11.32 \pm 0.87^{\mathrm{c}}$ \\
\hline
\end{tabular}

BB-bilberry wine; B-blackberry wine; C-cranberry wine; E-elderberry wine; R-raspberry wine; S-strawberry wine. $\mathrm{ULOQ}$ - uder limit of quantification; Different letters in rows indicate a significant difference $(p<0.05)$.

Glycerol was the main by-product in wines obtained in our study. Its content was between 4.95 and $10.81 \mathrm{~g} / \mathrm{L}$. It was also the main compound in five of the eight raspberry wines investigated by Duarte et al. [37], with contents ranging from 4.6 to $10.2 \mathrm{~g} / \mathrm{L}$. In subsequent research by Duarte et al. [38], glycerol was again the main compound in 11 out of the 16 studied raspberry wines. The glycerol contents were similar to those reported in their previous study, in the range of 4.45-10.11 g/L.

Acidity is one of the most important parameters in wine. In grape wines, it is mainly associated with organic acids such as tartaric, malic, acetic and lactic acids. Citric acid can have a significant effect on fruit wines, due to its high concentration in the raw material (for example in raspberries and blackberries). Malic acid also contributes to the acidity of fruit wine. Lactic and succinic acids 
are produced during fermentation. In our study, these two compounds were produced in amounts lower than $1 \mathrm{~g} / \mathrm{L}$. The predominant volatile acid is acetic acid, often expressed as the wine-quality parameter and known as volatile acidity. It is always formed during alcoholic fermentation. Higher concentrations of acetic acid can affect the organoleptic properties of wine. The acetic acid content was under the limit of quantification in the elderberry, raspberry, and strawberry wines. The highest content was observed in the bilberry wines.

Duarte et al. found a high content of succinic acid in raspberry wines [37]. In only one sample was it below $5.0(2.8 \mathrm{~g} / \mathrm{L})$, whereas, in the others, it was from 5.6 to $7.1 \mathrm{~g} / \mathrm{L}$ [38]. This is almost ten times higher than the levels of succinic acid found in our raspberry wines. Duarte et al. [38] also reported higher acetic acid contents, from 0.7 to $2.3 \mathrm{~g} / \mathrm{L}$. Most of the wines analyzed had no glucose.

In our elderberry wines, citric acid was the main acid, at concentrations of around $2.40 \mathrm{~g} / \mathrm{L}$. Malic acid was present in the next highest quantities $(1.15 \mathrm{~g} / \mathrm{L})$. This is consistent with results reported by Veberic et al. [39] for two cultivars and three selections of black elderberries from Slovenia. These authors found four acids (citric, malic, shikimic and fumaric) in the fruit.

Citric acid was present in the largest quantity, the content of malic acid was around three times smaller, and shikimic and fumaric acids composed on average $10 \%$ of the total.

Four of the six tested wines showed the presence of ascorbic acid. The concentration ranged from 0.03 to $0.08 \mathrm{~g} / \mathrm{L}$, for cranberry and bilberry wines, respectively. The low levels of vitamins in grape wines may explain the lack of relevant studies regarding the content of vitamins in fruit wines. Grape wines are reported to contain some B vitamins and very small amounts of vitamin $C$ and fat-soluble vitamins [26]. Vitamin C can be destroyed during processing and storage.

\subsection{Total Content of Polyphenols and Antioxidant Activity of Fruit Wines}

Of the wines investigated in our study, wines made from elderberry fruits showed the highest content of total polyphenols ( $1480.47 \mathrm{mg} / \mathrm{L}$ ) (Table 2). The content of total polyphenols in the remaining wines ranged from 408.03 to $759.42 \mathrm{mg}$ GAE/L. Low concentrations of polyphenols were observed in wines from cranberries and bilberries (below $500 \mathrm{mg} / \mathrm{L}$ ).

Table 2. Total polyphenols (mg/L) and antioxidant activity (mM of Trolox equivalents) of the investigated wines.

\begin{tabular}{|c|c|c|c|c|c|c|}
\hline & BB & B & C & E & $\mathbf{R}$ & S \\
\hline $\mathrm{TP}$ & $466.82 \pm 40.03^{a}$ & $759.42 \pm 52.30^{c}$ & $408.03 \pm 38.75^{a}$ & $1480.47 \pm 103.55^{\mathrm{d}}$ & $566.75 \pm 43.02^{b}$ & $525.60 \pm 50.74^{b}$ \\
\hline ABTS & $4.29 \pm 0.34^{c}$ & $5.84 \pm 0.34^{\mathrm{d}}$ & $3.03 \pm 0.19^{a}$ & $4.22 \pm 0.28^{c}$ & $3.49 \pm 0.23^{b}$ & $3.40 \pm 0.18^{\mathrm{a}}$ \\
\hline DPPH & $2.47 \pm 0.19^{c}$ & $2.55 \pm 0.16^{\mathrm{d}}$ & $1.12 \pm 0.07^{\mathrm{a}}$ & $1.87 \pm 0.09^{b}$ & $1.75 \pm 0.07^{b}$ & $1.66 \pm 0.12^{b}$ \\
\hline FRAP & $5.07 \pm 0.23^{c}$ & $6.45 \pm 0.45^{\mathrm{d}}$ & $3.32 \pm 0.25^{\mathrm{a}}$ & $5.07 \pm 0.39^{c}$ & $4.42 \pm 0.36^{\mathrm{b}}$ & $3.47 \pm 0.22^{\mathrm{a}}$ \\
\hline
\end{tabular}

In a study by Rupasinghe and Clegg [6], elderberry wines from Canada were found to contain $1753 \mathrm{mg}$ GAE/L. Aged elderberry wines from Slovenia analyzed by Schmitzer et al. [7] contained $1584.99 \mathrm{mg} / \mathrm{L}$ of total polyphenols. The pitchings (musts) were prepared in a similar manner to our elderberry wines, and the results are similar.

Most studies that have measured the content of total polyphenols in blackberry and bilberry wines used commercial products, so the methods of preparation are not known. Blackberry and bilberry wines from Illinois have been reported as having total polyphenol contents ranging from $188 \mathrm{mg}$ GAE/L to $1115 \mathrm{mg}$ GAE/L [40]. These levels are comparable to those for the blackberry and bilberry wines in our study. The blackberry and bilberry wines investigated by Kalkan Yildrim [41] had slightly higher concentrations of polyphenols. The blackberry wines studied by Ortiz et al. [42] contained from 1122 to $1400 \mathrm{mg} / \mathrm{L}$ of total polyphenols (depending on the pectinolytic enzyme used). The blackberry wines analyzed by Ljevar et al. [43] contained from 1055 to $2704 \mathrm{mg} / \mathrm{L}$. The highest contents of total 
polyphenols in blackberry wines have been reported by Mudnic et al. [44] (1697-2789 mg/L) and Mitic et al. [45] (1608-2836 mg/L).

The total polyphenol contents reported by Mitic et al. [45] and Ljevar et al. [43] for raspberry wines from Serbia and Croatia, respectively, were up to three-fold higher than those found in the raspberry wines in our study (1052-1490 and 1199-1840 mg/L, respectively). However, the preparation method again was different [46]. The raspberry and cranberry wines investigated by Rupasinghe and Clegg [6] contained 977 and $971 \mathrm{mg} / \mathrm{L}$ of total polyphenols, respectively.

The total content of polyphenols in our strawberry wines was almost three times lower than in wines obtained by Cakar et al. [1].

One method is usually insufficient to evaluate the antioxidant activity of a complex substance. In our study, three different assays were used to study the antioxidant properties of the wines. The antioxidant activity was determined in relation to $\mathrm{ABTS}^{+}$, DPPH and FRAP. Significant differences between ABTS and DPPH radicals were found in the examined wines, but similar trends were observed in different assays (FRAP, ABTS, and DPPH). The highest values were observed in blackberry wines, and the lowest for the cranberry wines (Table 2). As in a study by Ljevar et al. [43], the blackberry wines in our research also showed the highest antioxidant activity. The elderberry wines, despite having the highest polyphenol content, did not show high antioxidant activity. Heinonen et al. [5] evaluated the antioxidant activity of over 44 different fruit wines, mainly berry wines. The results showed that the total phenolic content did not correlate with the antioxidant activity. On the other hand, some studies have confirmed a strong positive correlation between the total antioxidant activity in fruit wines and total phenolics [6,46].

A study by Gao et al. [47] investigating the contribution of three different antioxidant fractions using an ABTS assay showed the total antioxidant capacity of phenolics, ascorbic acid, and lipophilic compounds to be slightly lower than those of crude extracts. The phenolic fraction made a major contribution to the total activity (about 75\%), followed by ascorbic acid (around 17\%). According to Brand-Williams et al. [48], ascorbic acid is one of the fastest reacting antioxidants. Observing changes in the phenolic profile during the winemaking process, Lingua et al. [49] noted that anthocyanins were the most important phenols in the wine samples. Most berry wines are rich in anthocyanins, but they react poorly in the Folin-Ciocalteu test, giving a poor correlation [50]. In general, different compounds were selected to correlate with the different in vitro assays. Depending on the chemical structure of the compounds and the mechanisms involved (hydrogen atom transfer, single electron transfer, reducing power, and metal chelation, among others), they react differently in various vitro assays [51].

\subsection{Polyphenols in Wines}

As there is no extensive literature on the subject, qualitative and quantitative analysis of the composition of polyphenols in the fruit wines was based mainly on the data concerning the juices and fruits from which the wines originated.

\subsubsection{Anthocyanins}

Cyanidin 3-glucoside was present in all the samples (Table 3; Figures S1, S4, S7, S10, S13 and S16). The highest level of cyanidin-glucoside was found in the blackberry wines $(30.26 \mathrm{mg} / \mathrm{L})$. Cyanidin 3-galactoside was found in four of investigated wines. Traces of cyanidin 3-rutinoside were found in the blackberry and raspberry wines. 
Table 3. Content of anthocyanins in the investigated wines $(\mathrm{mg} / \mathrm{L})$.

\begin{tabular}{|c|c|c|c|c|c|c|c|c|}
\hline Compound & $\begin{array}{c}{[\mathbf{M}+\mathbf{H}]^{+}} \\
m / z\end{array}$ & $\begin{array}{c}\mathrm{MS}^{2} \\
\mathrm{~m} / \mathrm{z}\end{array}$ & BB & B & $\mathrm{C}$ & $\mathrm{E}$ & $\mathbf{R}$ & $\mathrm{S}$ \\
\hline Cy-gal & 449 & 287 & $4.11 \pm 0.32$ & $1.11 \pm 0.08$ & $0.65 \pm 0.05$ & - & - & $0.32 \pm 0.03$ \\
\hline Cy-glc & 449 & 287 & LOQ & $30.26 \pm 2.89$ & $0.29 \pm 0.02$ & $6.19 \pm 0.57$ & $3.29 \pm 0.28$ & $0.30 \pm 0.03$ \\
\hline Cy-ara & 419 & 287 & - & - & $1.19 \pm 0.09$ & - & - & - \\
\hline Cy-xyl & 419 & 287 & - & $1.34 \pm 0.09$ & - & - & - & - \\
\hline Cy-rut & 595 & 287 & - & LOQ & - & - & LOQ & - \\
\hline Cy-soph & 611 & 287 & - & - & - & - & $14.98 \pm 1.32$ & - \\
\hline Сy-3(2glc) rut & 757 & 287 & - & - & - & - & $1.53 \pm 0.11$ & - \\
\hline Cy-3mal-glc & 535 & 287 & - & $1.32 \pm 0.12$ & - & - & - & - \\
\hline Cy-6mal-glc & 535 & 287 & - & $13.19 \pm 1.09$ & - & - & - & - \\
\hline Cy-sam & 579 & 537,357 & - & - & - & $46.51 \pm 4.34$ & - & - \\
\hline Cy-sam-5-glc & 744 & 287 & - & - & - & $23.07 \pm 2.02$ & - & - \\
\hline Cy-dioxalyl glc * & $593 / 594$ & 581,287 & - & $6.50 \pm 0.56$ & - & - & - & - \\
\hline$\sum C y$-deriv & & & 4.11 & 53.73 & 2.13 & 75.77 & 19.81 & 0.62 \\
\hline Dp-gal & 465 & 303 & $5.02 \pm 0.42$ & - & - & - & - & - \\
\hline Dp-glc & 465 & 303 & $0.81 \pm 0.06$ & - & - & - & - & - \\
\hline Dp-ara & 435 & 303 & $0.63 \pm 0.05$ & - & - & - & - & - \\
\hline$\sum D p-d e r$ & & & 6.46 & - & - & - & - & - \\
\hline Mv-gal & 493 & 331 & $1.01 \pm 0.09$ & - & - & - & - & - \\
\hline Mv-glc & 493 & 331 & $8.81 \pm 0.78$ & - & - & - & - & - \\
\hline Mv-ara & 463 & 331 & $1.02 \pm 0.09$ & - & - & - & - & - \\
\hline$\sum M v$ deriv & & & 10.84 & - & - & - & - & - \\
\hline Pg-glc & 433 & 271 & - & $1.20 \pm 0.09$ & - & - & - & $1.29 \pm 0.09$ \\
\hline Pg-rut & 579 & 433,271 & - & - & - & - & - & $0.67 \pm 0.06$ \\
\hline Pg-3-acetyl-glc & 475 & 271 & - & - & - & - & - & $0.49 \pm 0.04$ \\
\hline Pg-3mal-glc & 519 & 271 & - & - & - & - & - & $0.35 \pm 0.02$ \\
\hline Pg-3,5diglc & 595 & 433,271 & - & - & - & - & - & $0.24 \pm 0.02$ \\
\hline Pg-3glc-rut & $742 / 739$ & & - & - & - & - & $0.42 \pm 0.03$ & - \\
\hline E-(4,8)-Pg-glc & 721 & 559 & - & - & - & - & - & $0.25 \pm 0.02$ \\
\hline (epi)afzelechin-Pg-glc & 705 & $543,407,313$ & - & - & - & - & - & $0.25 \pm 0.02$ \\
\hline CP Pg-glc & 501 & 339 & - & - & - & - & - & $0.24 \pm 0.02$ \\
\hline
\end{tabular}


Table 3. Cont.

\begin{tabular}{|c|c|c|c|c|c|c|c|c|}
\hline Compound & $\begin{array}{c}{[\mathbf{M}+\mathbf{H}]^{+}} \\
m / z\end{array}$ & $\begin{array}{l}\mathrm{MS}^{2} \\
\mathrm{~m} / \mathrm{z}\end{array}$ & BB & B & $\mathrm{C}$ & $\mathrm{E}$ & $\mathbf{R}$ & $S$ \\
\hline$\sum P g$ deriv & & & - & 1.2 & - & - & 0.42 & 4.05 \\
\hline Pn-gal & 463 & 301 & $0.65 \pm 0.05$ & - & $0.71 \pm 0.06$ & - & - & - \\
\hline Pn-glc & 463 & 301 & $0.75 \pm 0.06$ & $0.82 \pm 0.07$ & LOQ & - & - & - \\
\hline Pn-ara & 433 & 301 & - & - & $0.63 \pm 0.05$ & - & - & - \\
\hline$\sum P n$ deriv & & & 1.40 & 0.82 & 1.34 & - & - & - \\
\hline Pt-gal & 479 & 317 & $0.49 \pm 0.03$ & - & - & - & - & - \\
\hline Pt-glc & 479 & 317 & $8.72 \pm 0.72$ & - & - & - & - & - \\
\hline Pt-ara & 449 & 317 & $1.29 \pm 0.09$ & - & - & - & - & - \\
\hline$\sum$ Pt deriv & & & 10.50 & - & - & - & - & - \\
\hline ni & 641 & $\begin{array}{c}623,505,477 \\
605,337\end{array}$ & - & - & - & $0.56 \pm 0.04$ & - & - \\
\hline total $* *$ & & & 37.03 & 56.37 & 3.47 & 76.33 & 22.32 & 6.09 \\
\hline
\end{tabular}

* or cyanidin 3-O- $\beta$-(6"-(3-hydroxy-3-methylglutaroyl)glucoside); ** of all peaks with max about $520 \mathrm{~nm}$; Cy—cyanidin; Dp—delphinidin; Mv—malvidin; Pg—pelargonidin; Pn—peonidin;

$\mathrm{Pt}$ - petunidin; gal—galactoside; glc—glucoside; ara—arabinoside, xyl—xyloside, rut—rutinoside, soph—sophoroside; sam—sambubioside; mal—malonyl, E—epicatechin; BB—bilberry

wine; B-blackberry wine; C—cranberry wine; E—elderberry wine; R—raspberry wine; S—strawberry wine; LOQ—under limit of quantitation. 
Cyanidin-sophoroside and cyanidin 3-(2G-glucosylrutinoside) were found in the raspberry wines, with Cy-soph as the main compound (Figure S13). Cyanidin 3-sambubioside and cyanidin 3-sambubioside-5-glucoside were present only in the elderberry wines, in quantities of $46.51 \mathrm{mg} / \mathrm{L}$ and $23.07 \mathrm{mg} / \mathrm{L}$, respectively (Figure S10).

Delphinidin derivatives were only present in the bilberry wines (Figure S1). Malvidin derivatives were also detected only in the bilberry wines, whereas pelargonidin derivatives were found in the wines made from blackberries and strawberries (Figures S4 and S16). Pelargonidin 3-glucoside was the main anthocyanin found in the strawberry wines. Carboxypyranopelargonidin-glucoside (CP Pg-glc) was also found in the strawberry wines. This compound had been identified previously in strawberries [52] and in strawberry-fermented products $[11,53]$.

Peonidins were found in the bilberry, blackberry and cranberry wines. Petunidins were found only in the bilberry wines.

The highest concentrations of anthocyanins were found in the elderberry wines $(76.33 \mathrm{mg} / \mathrm{L})$. The concentrations of anthocyanins in the blackberry wines were in excess of $50 \mathrm{mg} / \mathrm{L}$.

The main compound present in elderberry wines was cyanidin 3-sambubioside ( $46.51 \mathrm{mg} / \mathrm{L})$, and cyanidin 3-sambubioside-5-glucoside was present in the next largest quantities.

Our results differ significantly from those reported by Schmitzer et al. [7]. In their study of elderberry wines, cyanidin 3-glucoside was present at the highest concentrations in mature wine $(20.88 \mathrm{mg} / \mathrm{L})$, whereas, in our study, the concentration of this compound was $6.19 \mathrm{mg} / \mathrm{L}$. According to Schmitzer et al., cyanidin 3,5-diglucoside was present at a slightly lower concentration $(18.49 \mathrm{mg} / \mathrm{L})$, whereas, in our study, this compound was not found in the elderberry wines. Cyanidin 3,5-diglucoside and cyanidin 3-sambubioside-5-glucoside have similar retention times and coelution sometimes occurs [54]. However, no compound with a mass characteristic of cyanidin 3,5-diglucoside was found during our investigation. The sum of the concentrations of anthocyanins observed by Schmitzer et al. [7] based on HPLC analysis was approximately $50 \%$ higher than that in our elderberry wines.

The dominant compound in the blackberry wines we studied was cyanidin 3-glucoside, at a concentration of $30.26 \mathrm{mg} / \mathrm{L}$. In domestic wines obtained by Mitic et al. [45], the content of cyanidin 3 -glucoside was around 10 times higher. Cyanidin xyloside was present in the next highest concentration, which was again much higher than in the blackberry wines in our study. Cyanidin 3-rutinoside was the main compound in the blackberry wines analyzed by Ljevar et al. [43]. Only small amounts of this compound were found in the blackberry wines we studied. Relatively large amounts of cyanidin 3-glucoside acylated with malonic acid were detected in our study, at a concentration approximately two-fold lower than those for cyanidin 3-glucoside. This compound has been identified previously as occurring in blackberries [54-58] but was identified here for the first time in blackberry wine.

Compared to those analyzed by Hornedo-Ortega et al. [53], the strawberry wines in our study contained much lower levels of both pelargonidin 3-glucoside and pelargonidin 3-rutinoside. However, the wines studied by Hornedo-Ortega et al. were analyzed immediately following the fermentation process, whereas ours were tested after 5 months of aging. Other authors have noted a $63-85 \%$ reduction in these compounds during the fermentation and storage $[59,60]$. Relatively large amounts of one acylated derivative and one diglucoside derivative of pelargonidin were found in our wines. Hornedo-Ortega et al. [53] showed that fermentation significantly increases the levels of diglucoside in strawberry wines (2.5- and 6.2-fold for 2012 and 2013 vintages, respectively).

All of the wines in our study were prepared using thermal treatment. As observed by Behrends and Weber [10], pre-fermentative heat treatment influences the characteristics of wine. This was confirmed in our previous research [2,3]. The bilberry wines investigated by Behrends and Weber [10] had almost the same anthocyanin profiles as juices when pre-fermentative heat treatment was applied. With warm treatment $\left(70^{\circ} \mathrm{C}\right)$, the ratio of glucosides to galactosides and arabinosides was 47.9:32.1:20. In the bilberry wines we studied, the ratio was 58.9:32:9.1. Some of the fruits in our study (including bilberries) were also treated with pectinase. As observed by Buchert et al. [61], enzyme-assisted bilberry juice production leads to greater losses of galactosides. 


\subsubsection{Phenolic Acids}

The largest quantities of hydroxycinnamic acids were found in elderberry wines $(150.79 \mathrm{mg} / \mathrm{L})$. The lowest levels were observed in the strawberry wines $(13.43 \mathrm{mg} / \mathrm{L})$ (Table 4). None of the acids were present in all of the wines (Figures S2, S5, S8, S11, S14 and S17).

The main acids found in the elderberry wines were neochlorogenic, chlorogenic and caffeic acids (Figure S11). Schmitzer et al. [7] analyzed only neochlorogenic and chlorogenic acids. The neochlorogenic acid content was higher in our samples. It is difficult to compare results for chlorogenic acid. During chromatographic analysis (HPLC), chlorogenic acid probably coeluted with caffeic acid and one large peak was observed. Using a mass spectrometer, a mass of 179 (typical for caffeic acid) proved dominant. Caffeic acid hexoside $(341 \mathrm{~m} / \mathrm{z}), p$-coumaric acid $(163 \mathrm{~m} / \mathrm{z})$ and p-coumaric acid derivative $(525 \mathrm{~m} / \mathrm{z})$ were also found. Caffeic acid and its derivative, caffeic acid hexoside, were the main acids in the bilberry wines, accounting for almost $75 \%$ of the total acid content (Figure S2). Caffeic acid was also the main compound in the raspberry wines. The dominant acids in the blackberry wines (around 85\%) and strawberry wines (around 47\%) were p-coumaroylhexosides. Cakar et al. [1] found small amounts $(4.16-2.83 \mu \mathrm{g} / \mathrm{mL})$ of p-coumaric acid in strawberry wines, which was about $10 \%$ of the total phenolic acid content. These authors identified chlorogenic acid chlorogenic acid as a main compound $(290-335 \mu \mathrm{g} / \mathrm{mL})$ followed by the caffeic acid. No chlorogenic acid was identified in any of the 90 strawberry varieties investigated by Nowicka et al. [62]. A compound with very similar MS $(\mathrm{m} / \mathrm{z} 355)$ was identified as 1-O-trans-cinnamoyl-glucose. This compound had the highest content in almost all investigated varieties, followed by $p$-coumaroyl-glucosides. Nowicka et al. [62] also identified 1-O-feruloylglucose. In our investigated wines, 5-hydroxyferuloylhexoside was identified. This compound probably formed during fermentation.

\subsubsection{Flavonols}

Flavonols were present in relatively low concentrations compared to the other groups of studied compounds, from 0.87 to $9.27 \mathrm{mg} / \mathrm{L}$ (Table 5). The lowest concentrations occurred in wines made from raspberries, strawberries, bilberries and blackberries $(0.87-1.81 \mathrm{mg} / \mathrm{L})$, and the highest in wines made from elderberries $(9.27 \mathrm{mg} / \mathrm{L})$. 
Table 4. Content of hydroxycinnamic acid derivatives in the investigated wines $(\mathrm{mg} / \mathrm{L})$.

\begin{tabular}{|c|c|c|c|c|c|c|c|c|}
\hline & $\begin{array}{c}{[\mathbf{M}-\mathbf{H}]^{-}} \\
m / z\end{array}$ & $\begin{array}{c}\mathrm{MS}^{2} \\
\mathrm{~m} / \mathrm{z}\end{array}$ & BB & B & $\mathrm{C}$ & $\mathrm{E}$ & $\mathbf{R}$ & $\mathrm{S}$ \\
\hline malonylo-CQA & 439,396 & $395,219,173,295,289$ & - & - & - & - & - & $0.74 \pm 0.05$ \\
\hline neoChA & 353 & 191,179 & - & $6.42 \pm 0.56$ & - & $24.99 \pm 2.08$ & - & - \\
\hline $\mathrm{CAH}$ & 341 & $197,135,161,179$ & $10.97 \pm 0.93$ & LOQ & $10.89 \pm 0.87$ & $9.98 \pm 0.78$ & $4.41 \pm 0.37$ & - \\
\hline $\mathrm{pCoH}$ & 325 & $163,145,187,265$ & - & $54.35 * \pm 4.89$ & - & - & $12.35^{*} \pm 0.96$ & $6.31 \pm 0.54$ \\
\hline ChA & 353 & 191,179 & LOQ & $2.01 \pm 0.17$ & $5.59 \pm 0.45$ & coeluted & - & - \\
\hline $\mathrm{CA}$ & 179 & 135 & $44.10 \pm 3.99$ & & $8.67 \pm 0.78$ & $60.04 \pm 5.33$ & $15.32 \pm 1.03$ & \\
\hline FA & 193 & 134 & - & - & - & - & - & LOQ \\
\hline $\mathrm{p}-\mathrm{CoA}$ & 163 & 119 & $14.77 \pm 1.23$ & - & - & $13.44 \pm 1.02$ & - & $4.60 \pm 0.34$ \\
\hline pCo der & 411 & & $2.27 \pm 0.19$ & - & - & - & - & - \\
\hline pCo der & 525 & & - & - & - & $19.86 \pm 1.88$ & - & - \\
\hline $\begin{array}{l}\text { 5-hydroxy } \\
\text { F hex }\end{array}$ & 371 & $281,251,221,209$ & - & - & - & - & - & $1.78 \pm 0.16$ \\
\hline $\mathrm{ni}$ & 207 & & - & - & - & $16.20 \pm 1.52$ & - & - \\
\hline total & & & 73.48 & 63.95 & 37.06 & 150.79 & 32.18 & 13.43 \\
\hline
\end{tabular}

- not identified in this wine; malonylo-CQA-malonylo-caffeoylquinic acid; neoChA-neochlorogenic acid; $\mathrm{CAH}-$ caffeic acid hexoside; $\mathrm{ChA}$-chlorogenic acid; $\mathrm{pCoH}-\mathrm{p}$-coumaroylhexoside; $\mathrm{CA} —$ caffeic acid; FA—-ferulic acid; pCoA-p-coumaric acid; pCoA der—p-coumaric acid derivative; 5-hydroxyFhex—5-hydroxyferuloyl hexose; tr-traces; BB - bilberry wine; B-blackberry wine; C—cranberry wine; E—elderberry wine; R—raspberry wine; S—-strawberry wine; LOQ—under limit of quantitation; * -two peaks. 
Table 5. Flavonols contents in the investigated wines (mg/L).

\begin{tabular}{|c|c|c|c|c|c|c|c|c|}
\hline & $\begin{array}{c}{[\mathbf{M}-\mathbf{H}]^{-}} \\
m / z\end{array}$ & $\begin{array}{c}\text { MS MS }^{2} \\
m / z\end{array}$ & BB & B & C & $\mathbf{E}$ & $\mathbf{R}$ & $\mathrm{S}$ \\
\hline M-glc & 479 & 317 & $0.27 \pm 0.02$ & - & - & - & - & - \\
\hline M-ara & 449 & 317 & - & - & $0.01 \pm 0.00$ & - & - & - \\
\hline M-xyl & 449 & 317 & - & - & $0.02 \pm 0.00$ & - & - & - \\
\hline M-malonylglc & 565 & 317 & - & - & - & - & - & LOQ \\
\hline M-dimethoxy-hex & 507 & 344,387 & - & - & $0.01 \pm 0.00$ & - & - & - \\
\hline M & 317 & $179,151,192$ & $0.28 \pm 0.02$ & - & $0.78 \pm 0.06$ & - & - & - \\
\hline$\sum \mathrm{M}$ derivatives & & & 0.55 & - & 0.82 & - & - & LOQ \\
\hline Q-gal & 463 & 301 & - & $0.36 \pm 0.03$ & $0.05 \pm 0.00$ & $0.10 \pm 0.01$ & $0.11 \pm 0.01$ & - \\
\hline Q-glc & 463 & 301 & $0.17 \pm 0.01$ & $0.07 \pm 0.01$ & - & $2.36 \pm 0.18$ & $0.05 \pm 0.00$ & $0.19 \pm 0.02$ \\
\hline Q-ara & 433 & 301 & - & - & $0.12 \pm 0.01$ & - & - & - \\
\hline Q-rut & 609 & $301,343,463$ & LOQ & $0.09 \pm 0.00$ & - & $5.04 \pm 0.42$ & $0.10 \pm 0.01$ & - \\
\hline Q-pent & 433 & $301,179,151$ & - & LOQ & - & - & - & - \\
\hline Q-xyl & 433 & 301 & $0.05 \pm 0.00$ & - & $0.20 \pm 0.02$ & - & - & - \\
\hline Q-rha & 447 & 301 & - & - & $0.25 \pm 0.02$ & - & - & - \\
\hline Q-gluc & 477 & 301 & - & $0.31 \pm 0.02$ & - & - & $0.09 \pm 0.01$ & $0.38 \pm 0.03$ \\
\hline Q-diglc & 625 & $\begin{array}{c}283,255,463 \\
301\end{array}$ & LOQ & (1) & - & - & 年 & 年 \\
\hline Q-2gal-rha & 609 & $283,255,300$ & - & - & - & - & $0.09 \pm 0.01$ & - \\
\hline Q-3acetylhex & 505 & 463,301 & - & $0.39 \pm 0.03$ & - & - & - & LOQ \\
\hline Q-methoxyhex & 493 & 463,301 & $0.11 \pm 0.01$ & - & - & - & - & - \\
\hline $\begin{array}{l}\text { Q3[6"(3hydroxy-3 } \\
\text { methyl-glut)] gal }\end{array}$ & 607 & 463,301 & - & $0.51 \pm 0.04$ & - & - & - & - \\
\hline Q-malonyl-glc & 549 & 503,301 & - & - & - & LOQ & - & - \\
\hline methoxyQ-xyl & 447 & 300 & - & - & $0.01 \pm 0.00$ & - & - & - \\
\hline Q-benzoyl gal & 567 & 300 & - & - & $0.05 \pm 0.00$ & - & - & - \\
\hline $\mathrm{Q}$ & 301 & $179,151,257$ & $0.28 \pm 0.02$ & $0.07 \pm 0.00$ & $1.56 \pm 0.14$ & $1.35 \pm 0.12$ & $0.04 \pm 0.00$ & $0.05 \pm 0.00$ \\
\hline IsoQ & 509 & 463 & - & - & - & LOQ & - & - \\
\hline dihydroQ glc & 465 & 285,151 & - & LOQ & - & - & - & - \\
\hline I=3-methylQ & 315 & $631 / 632,315$ & - & - & - & $0.19 \pm 0.02$ & - & - \\
\hline$\sum \mathrm{Q}$ derivatives & & & 0.63 & 1.80 & 2.24 & 9.04 & 0.48 & 0.62 \\
\hline
\end{tabular}


Table 5. Cont.

\begin{tabular}{|c|c|c|c|c|c|c|c|c|}
\hline & $\begin{array}{c}{[\mathbf{M}-\mathbf{H}]^{-}} \\
m / z\end{array}$ & $\begin{array}{c}\text { MS MS }^{2} \\
m / z\end{array}$ & BB & B & $\mathrm{C}$ & $\mathrm{E}$ & $\mathbf{R}$ & $\mathrm{S}$ \\
\hline K-gal & 447 & 285 & $0.16 \pm 0.01$ & - & - & - & $0.10 \pm 0.01$ & - \\
\hline K-glc & 447 & 285 & $0.16 \pm 0.01$ & - & - & - & - & $0.15 \pm 0.01$ \\
\hline K-rut & 593 & 285 & - & - & - & $0.22 \pm 0.02$ & - & - \\
\hline K-pent & 417 & $241,152,285$ & - & - & - & - & - & LOQ \\
\hline K-gluc & 461 & 415,285 & - & - & - & - & $0.26 \pm 0.02$ & $0.15 \pm 0.02$ \\
\hline $\mathrm{K}$ & 285 & 267 & - & - & - & - & $0.03 \pm 0.00$ & - \\
\hline dihydroK-glc & 449 & $\begin{array}{l}431,287,269 \\
259,243,179\end{array}$ & - & LOQ & - & - & - & LOQ \\
\hline dihydroK-rha & 433 & 287 & - & LOQ & - & - & - & - \\
\hline $\mathrm{K} 3\left(6^{\prime \prime}-p-\mathrm{Co}\right)$ glc & 593 & & - & LOQ & - & - & - & - \\
\hline$\sum K$ derivatives & & & 0.16 & - & - & 0.22 & 0.39 & 0.30 \\
\hline total & & & 1.43 & 1.81 & 3.02 & 9.27 & 0.87 & 0.92 \\
\hline
\end{tabular}

- not identified in this wine; M-Myricetin; Q-Quercetin; K—Kaempferol; I—Isorhamnetin; gal—galactoside; glc—glucoside; ara—arabinoside, xyl—xyloside, rut—rutinoside, soph—sophoroside; rha—rhamnoside; glu—glucuronide; glut—glutaroyl; $\mathrm{p}$-Co—p-coumaroyl; pent—pentoside; hex—hexoside; BB—bilberry wine; B—blackberry wine; C—cranberry wine; E-elderberry wine; R—raspberry wine; S—strawberry wine; LOQ—under limit of quantitation. 
In terms of qualitative composition, more than $80 \%$ of all identified flavonols in the elderberry wines were quercetin and its derivatives (Figure S12). Myricetin and its derivatives were found in the cranberry and bilberry wines (Figures S3 and S9), while trace amounts of myricetin malonylglucoside were found in strawberry wines. Quercetin 3-rutinoside was the main flavonol in the elderberry wines, comprising $56 \%$ of the total for this group of compounds. Flavonols were found to dominate in the elderberry wines studied by Schmitzer et al. [7], at concentrations around 10 times higher than in our wines, with the highest concentrations occurring in young wines. The same authors detected quercetin rutinoside and glucoside in the highest and second-highest concentrations. Kaempferol-rutinoside was present in the lowest quantity, at a concentration of $1.1 \mathrm{mg} / \mathrm{L}$, whereas, in our elderberry wines, the concentration was $0.22 \mathrm{mg} / \mathrm{L}$. The elderberry wines in our study contained more than $1 \mathrm{mg} / \mathrm{L}$ of quercetin. Fruit wines made from cherries, blackberries and raspberries were found by Mitic et al. [45] to contain derivatives of quercetin and kaempferol. The same authors reported the presence of kaempferol derivatives in blackberry wines, at levels of $0.30-0.85 \mathrm{mg} / \mathrm{L}$. However, we did not detect these compounds in our blackberry wines (Figure S6). The content of quercetin derivatives in the raspberry wines studied by Mitic et al. [45] ranged from 0.98 to $1.80 \mathrm{mg} / \mathrm{L}$, compared with only $0.48 \mathrm{mg} / \mathrm{L}$ in our study. We also found kaempferol derivatives in raspberry wines (Figure S15), at a concentration of $0.39 \mathrm{mg} / \mathrm{L}$. The strawberry wines investigated by Cakar et al. [1] contained three compounds from the group of flavonols: quercetin, quercetin 3-rutinoside (rutin) and kaempferol. Only small amounts of quercetin were found in our strawberry wines, less than $10 \%$ of the total Q-derivatives content. We did not identify Q-rut, but we found significant amounts of Q-glucoside and Q-glucuronide (Figure S18). We were unable to identify kaempferol in the strawberry wines, but we did find its derivatives, K-glucoside and K-glucuronide, as well as traces of K-pentoside and dihydroK-glucoside.

\subsubsection{Other Bioactive Compounds}

Other bioactive compounds were tentatively identified using LC-MS ${ }^{\mathrm{n}}$ (Table 6). Sixteen acids were found, including hydroxybenzoic acids. Cinnamic acid was identified in all the samples. Shikimic acid was found in all of the wines except cranberry wine. In the blackberry wines, two forms of abscisic acid were identified: abscisic acid D-glucopyranosyl ester (ABA-GE) and ursolic acid.

Ellagic acid was identified in five of the six wines in our study, but its derivatives were found mainly in the wines made from blackberries (five compounds), strawberries (three compounds) and raspberries (two compounds). Of the twelve ellagitannins we identified, as many as ten were found in the blackberry wines. Five were found in the strawberry wines and four were identified in the raspberry wines. Three gallic acid derivatives were identified: one in the bilberry wines, one in the cranberry wines and one in the strawberry wines. Procyanidins are another important group of polyphenols. In total, 20 compounds from this group were identified. Of these, 14 were found in the cranberry wines, which were the richest and most diverse source of procyanidins.

Seven compounds from this group were identified in the strawberry wines, including two afzelechin-catechin derivatives.

Cakar et al. [1] identified hydroxybenzoic acids in strawberry wines. Gallic acid had the highest concentration, followed consecutively by p-hydroxybenzoic, protocatechuic and vanillic acids. We identified two of these hydroxybenzoic acids in our strawberry wines (Table 6). We also found two derivatives of: protocatechuic acid hexoside and 1-O-protocatechuylhexoside. Vanillic acid was not found.

Cakar et al. also found significant amounts of ellagic acid in their strawberry wines. We identified this compound in five wines (was not present in cranberry wines) (Table 6). 
Table 6. Other compounds identified in investigated wines.

\begin{tabular}{|c|c|c|c|c|c|c|c|c|c|}
\hline Tentative Compound & $\lambda \max$ & $\begin{array}{c}{[\mathbf{M}-\mathbf{H}]^{-}} \\
m / z\end{array}$ & $\begin{array}{c}\mathrm{MS}^{2} \\
\mathrm{~m} / \mathrm{z}\end{array}$ & BB & B & C & E & $\mathbf{R}$ & $\mathrm{S}$ \\
\hline \multicolumn{10}{|l|}{ acids } \\
\hline cinnamic acid & 225 & 147 & $129,85,87,103$ & + & + & + & + & + & + \\
\hline vanillic acid & 271 & 167 & & - & - & + & - & - & _ \\
\hline ascorbic acid & 253 & 175 & $129,115,157,85$ & + & + & + & - & + & - \\
\hline shikimic acid & 270 & 173 & 127,83 & + & + & - & + & + & + \\
\hline p-hydroxybenzoic acid & 277 & 137 & $93,119,110$ & - & - & + & + & + & + \\
\hline benzoic acid & 275 & 121 & $77,121,92$ & - & - & + & - & - & - \\
\hline hydroxybenzoyl-glc & 276,309 & 299 & 137 & - & - & - & - & - & + \\
\hline protocatechuic acid & 260,294 & 153 & $109,125,83$ & + & + & + & + & - & - \\
\hline protocatechuic acid hex & & 315 & 152,108 & - & + & + & - & - & + \\
\hline 1-O-protocatechuylhex & & 285 & 152,108 & - & - & + & - & - & + \\
\hline sinapic acid hex & 265,382 & 385 & 339 & - & - & - & + & - & - \\
\hline brevifolin carboxylic acid & 281 & 291 & $248,247,203$ & - & - & - & - & - & + \\
\hline cis-ABA & & 263 & 153 & + & + & - & - & - & - \\
\hline trans-ABA & & 263 & 204 & + & + & - & - & - & - \\
\hline ABA-GE & & 425 & 263 & - & + & - & - & - & - \\
\hline ursolic acid=prunol & & 455 & 515 & - & + & - & - & - & - \\
\hline \multicolumn{10}{|l|}{ Ellagic acid derivatives } \\
\hline ellagic acid & $245,278,382$ & $\begin{array}{c}603[2 \mathrm{M}] \\
301\end{array}$ & $467,439,179,273,257$ & + & + & - & + & + & + \\
\hline ellagic acid pent & 231 & 433 & $300 / 301$ & - & + & - & - & + & + \\
\hline ellagic acid hex & 255,362 & 463 & 301 & - & + & - & - & - & - \\
\hline ellagic acid deoxyhex & 231,364 & 447 & $300 / 301,257$ & - & - & - & - & - & + \\
\hline dimethyl ellagic acid pent & & 461 & $300 / 301,145$ & - & + & - & - & - & - \\
\hline ellagic acid acetyl-ara & 235,273 & 475 & 301 & - & - & - & - & + & - \\
\hline methylellagic acid gluc & 253,361 & 491 & $315,301,257,229$ & - & + & - & - & - & - \\
\hline ellagic acid acetyl-methylpent & 254,364 & 489 & $301,257,229$ & - & + & - & - & - & - \\
\hline ellagic acid rha & & 447 & 301 & - & - & - & - & - & + \\
\hline
\end{tabular}


Table 6. Cont.

\begin{tabular}{|c|c|c|c|c|c|c|c|c|c|}
\hline Tentative Compound & $\lambda \max$ & $\begin{array}{c}{[\mathbf{M}-\mathbf{H}]^{-}} \\
\quad m / z\end{array}$ & $\begin{array}{c}\mathrm{MS}^{2} \\
\mathrm{~m} / \mathrm{z}\end{array}$ & BB & B & $\mathrm{C}$ & $\mathrm{E}$ & $\mathbf{R}$ & $S$ \\
\hline \multicolumn{10}{|l|}{ Ellagitannins } \\
\hline ellagitannin & 232,270 & 679 & 664 & - & - & - & - & - & + \\
\hline HHDP glc & & 481 & 301,275 & - & + & - & - & - & + \\
\hline galloyl-bis-HHDP glc & & 935 & 633,301 & - & + & - & - & - & - \\
\hline galloyl-HHDP glc & 280 & $633,632.6$ & $481,301,613,301,481,783$ & - & + & - & - & - & + \\
\hline bis-HDDP-glc & 280 & 783 & $301,481,257,229$ & - & + & - & - & - & + \\
\hline tris-galloyl-HHDP hex & & 951 & $907,783,605,301$ & - & + & - & - & - & + \\
\hline $\begin{array}{c}\text { davuriicin M1 } \\
\text { (diHHDP-glc-galloyl-ellagic acid) }\end{array}$ & & $617[\mathrm{M}-2 \mathrm{H}]^{2-}, 1236$ & $933,631,301$ & - & + & - & - & - & - \\
\hline Sanguiin H-10 isomer (2) & 232 & {$[1567]^{-},[783]^{2-}$} & $935,633,301$ & - & + & - & - & + & - \\
\hline Sanguiin $\mathrm{H}-2$ & 245 & $1103,[551]^{2}$ & $935,633,469,301$ & - & - & - & - & + & - \\
\hline castalagin/vescalagin & & 933 & 301 & - & + & - & - & - & - \\
\hline pedunculagin/sanguin isomer $\mathrm{H} 10$ & 268,377 & 783 & $633,301,1266,934,1104$ & - & + & - & - & + & - \\
\hline Sanguin H6 & $340,352,366$ & $\begin{array}{c}935 / 934[\mathrm{M}-2 \mathrm{H}]^{2-} \\
1870\end{array}$ & $\begin{array}{c}633,301,897,916,783,1567,1235 \\
633,301\end{array}$ & - & + & - & - & + & - \\
\hline \multicolumn{10}{|l|}{ Gallic acid derivatives } \\
\hline gallic acid & 286 & 169 & 125 & + & - & - & - & - & + \\
\hline methyl gallate & & $183 / 184$ & & - & - & + & - & - & - \\
\hline galloylquinic acid & & 343 & 191,169 & - & - & - & - & - & + \\
\hline $\begin{array}{l}\text { gallic acid deriv } \\
\text { Procyanidins }\end{array}$ & 280,451 & 635 & 483 & + & - & - & - & - & - \\
\hline epigallocatechin & 283 & 611 & & - & + & - & - & - & + \\
\hline gallocatechin & & $306 / 305$ & & - & + & - & - & - & - \\
\hline catechin & 280 & 289 & $245,205,179$ & + & + & + & - & - & + \\
\hline epicatechin & 285 & 289 & $245,205,271,179$ & - & + & - & - & + & - \\
\hline Procyanidin dimer & 277 & 575 & $490,499,413$ & - & - & + & - & + & - \\
\hline
\end{tabular}


Table 6. Cont.

\begin{tabular}{|c|c|c|c|c|c|c|c|c|c|}
\hline Tentative Compound & $\lambda \max$ & $\begin{array}{c}{[\mathbf{M}-\mathbf{H}]^{-}} \\
m / z\end{array}$ & $\begin{array}{c}\mathrm{MS}^{2} \\
\mathrm{~m} / \mathrm{z}\end{array}$ & BB & B & C & $\mathbf{E}$ & $\mathbf{R}$ & $\mathrm{S}$ \\
\hline \multirow{5}{*}{ 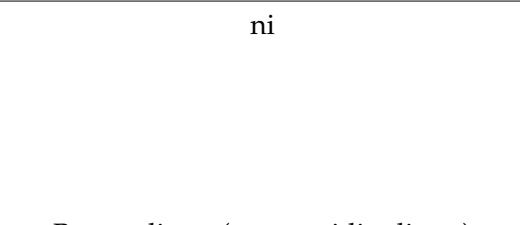 } & 277 & 575 & $377,395,333,273,1007$ & - & - & + & - & - & - \\
\hline & 277 & 575 & $\begin{array}{c}863 / 864,499,413,267,289,699 \\
1025\end{array}$ & - & - & + & - & - & - \\
\hline & 277 & 575 & $499,490,861,423,289,999,1025$ & - & - & + & - & - & - \\
\hline & 277 & 575 & $395,351,371,289,1025$ & - & - & + & - & - & - \\
\hline & 277 & 575 & $423,449,539,285,557,1025$ & - & - & + & - & - & - \\
\hline B type dimer (procyanidin dimer) & 282 & 577 & $425,407,451$ & + & - & - & - & - & + \\
\hline \multirow[t]{2}{*}{ Procyanidin B1 } & 278 & 577 & 425,407 & - & + & + & - & - & + \\
\hline & & 577 & $397,373,273,415,1019$ & - & - & + & - & - & - \\
\hline Procyanidin trimer (Atype) & 280 & 863 & $711,411,559,693$ & - & - & + & - & - & - \\
\hline Procyanidin trimer (Btype) & 281 & 865 & $695,577,407,847$ & - & - & + & - & - & + \\
\hline $\begin{array}{c}\text { Procyanidin tetramer } \\
\text { (Btype) }\end{array}$ & 276 & $1152 / 1153$ & & - & - & + & - & - & - \\
\hline $\begin{array}{c}\text { dimer (Cat-Afz) } \\
\text { propelargonidin dimer }\end{array}$ & 279 & 561 & $289,543,435$ & - & + & - & - & - & + \\
\hline trimer A type & 276 & 863 & $711,693,411,459,559,289$ & - & - & + & - & - & - \\
\hline ni & & 863 & $575,711,693,559,285,1601$ & - & - & + & - & - & - \\
\hline $\begin{array}{c}\text { Trimer (Cat-Cat-Afz) } \\
\text { Flavone. }\end{array}$ & \multicolumn{8}{|c|}{ Flavone. } & + \\
\hline apigenin pent & & 401 & 269,161 & - & + & - & - & - & - \\
\hline $\begin{array}{l}\text { apigenin glc } \\
\text { Biflavonoids }\end{array}$ & \multicolumn{8}{|c|}{ Biflavonoids } & - \\
\hline pentahydroxyflavan dimer & 250 & 579 & 271,289 & - & - & - & - & + & - \\
\hline $\begin{array}{c}\text { tetrahydroxyflavan-pentahydroxyflavan } \\
\text { dimer } \\
\text { Stilbenoids }\end{array}$ & & 563 & $273,291,411,427$ & - & - & - & - & + & - \\
\hline $\begin{array}{l}\text { trans-resveratrol-glc } \\
\text { Unknown compounds }\end{array}$ & & 389 & 185,227 & + & + & - & - & - & - \\
\hline ni & & 340 & $294,188,161$ & - & - & - & + & - & - \\
\hline $\mathrm{ni}$ & $226,278,397$ & 405 & 225 & - & - & - & + & - & - \\
\hline ni & 259 & 391 & $217,373,111,216,191$ & - & - & - & - & + & - \\
\hline ni & 226,284 & 379 & 241 & - & - & - & + & - & - \\
\hline $\mathrm{ni}$ & 281 & 333 & $165,289,183$ & - & - & + & - & - & - \\
\hline
\end{tabular}

ni-not identified compound; +- present; - —absent; glc—glucoside, hex—hexoside, ABA—abscisic acid; ABA-GE—abscisic acid D-glucopyranosyl ester; BB—bilberry wine; B—blackberry wine; $\mathrm{C}$-cranberry wine; E-elderberry wine; $\mathrm{R}$-raspberry wine; $\mathrm{S}$ - strawberry wine. 


\subsection{Effect of Dealcoholated Fruit Wines on Microbial Growth}

We studied the effects of the compounds present in the dealcoholated fruit wines on the growth of various microorganisms (Table 7). The berry wines had no inhibitory effect on the growth of Salmonella Enteritidis, Staphylococcus aureus bacteria and Candida albicans yeast. The only growth inhibitors for Escherichia coli ATCC 1053 were bioactive compounds found in the strawberry wines. The resulting zones of inhibition were $2.67 \mathrm{~mm}$. The strain Bacillus cereus ŁOCK O807 was the most susceptible to the effects of the wines. Its growth was inhibited by the compounds in five of the wines. Only the elderberry wines had no effect on the growth of this strain. The most extensive inhibition zones resulted from the impact of raspberry wines.

Table 7. Inhibition zones (mm).

\begin{tabular}{ccccccc}
\hline & $\begin{array}{c}\text { Escherichia } \\
\text { coli }\end{array}$ & $\begin{array}{c}\text { Salmonella } \\
\text { Enteritidis }\end{array}$ & Bacillus cereus & $\begin{array}{c}\text { Listeria } \\
\text { monocytogenes }\end{array}$ & $\begin{array}{c}\text { Staphylococcus } \\
\text { aureus }\end{array}$ & $\begin{array}{c}\text { Candida } \\
\text { albicans }\end{array}$ \\
\hline Bilberry & - & - & $1.73 \pm 0.12^{\mathrm{A}}$ & - & - & - \\
Blackberry & - & - & $2.00 \pm 0.25^{\mathrm{bA}}$ & $1.00 \pm 0.00^{\mathrm{aA}}$ & - & - \\
Cranberry & - & - & $1.83 \pm 0.23^{\mathrm{aA}}$ & $2.33 \pm 0.58 \mathrm{aB}$ & - & - \\
Elderberry & - & - & - & - & - & - \\
Raspberry & - & - & $4.00 \pm 0.71^{\mathrm{B}}$ & - & - & - \\
Strawberry & $2.67 \pm 0.58^{\mathrm{a}}$ & - & $1.83 \pm 0.23^{\mathrm{aA}}$ & - & - & - \\
\hline
\end{tabular}

- No inhibitory effect; $\mathrm{a}, \mathrm{b}$-Different letters indicate a significant difference in rows $(p<0.05)$; A,B-Different letters indicate a significant difference in columns $(p<0.05)$.

Growth of Listeria monocytogenes ATCC 13932 was inhibited by the bioactive compounds present in two of the wines. The cranberry and blackberry wines had an inhibitory effect on the growth of these bacteria, with a zones of 2.33 and $1.00 \mathrm{~mm}$, respectively.

The elderberry wines did not inhibit the growth of any of the microorganism, despite having the highest total polyphenol concentration and the highest content of anthocyanins, which some authors consider to be one of the main providers of antimicrobial properties [17,18]. The growth of Bacillus cereus was inhibited to the greatest extent by the wine made from raspberries. These fruits are a rich source of ellagitannins, which have strong antimicrobial activity. In the raspberry wines, we identified Sanguiin H2, H6 and Sanguiin H10 isomers (Table 6). Other compounds from this group (HHDP glucosides and their derivatives) were identified in the blackberry and strawberry wines. The cranberry wines did not contain ellagitannins, but a wide range of procyanidins were identified, including type A. Proanthocyanidin extracts of cranberries investigated by Kylli et al. [63] showed strong antimicrobial effects against Staphylococcus aureus, whereas they had no effect on other bacterial strains such as Salmonella Typhimurium and Escherichia coli. Phenolic extracts of lingonberry and cranberry had an antibacterial effect on Gram-positive pathogens including Staphylococcus, Bacillus and Clostridium, but only had weak or no antimicrobial activity on Gram-negative strains of Salmonella. However, Listeria monocytogenes was not inhibited by by either the lingonberry extract or cranberry extract [21,64].

Based on the results of these preliminary studies on the dealcoholated red berry wines, we see the possibility of using them as a food additive, improving safety and extending shelf life. As previously mentioned, some of the microorganisms tested may already be found in the oral cavity, so the wines could have an impact at this stage. Regarding the upper respiratory tract, oral invasion in immunosuppressed patients may be more frequent than previously documented, as the oral cavity can be colonized by B. cereus either by inhaling spores or by eating food contaminated with B. cereus [32]. Foci can occur when bacteria become trapped in the furrows in the oral cavity, where they grow and release toxins that spread to adjacent tissues and other parts of the body. However, further studies are necessary to investigate the action of the wines against pathogens in the human gastrointestinal tract. 


\section{Conclusions}

In this study, about 150 compounds were identified in berry wines, including anthocyanins (34), hydroxycinnamic acids (12) and flavonols (36). Some of these compounds were identified for the first time in berry wines. The largest number of bioactive compounds was identified in the blackberry wines (59 compounds). All of the wines were rich in polyphenols. Elderberry wines were the richest source of polyphenols (over $1000 \mathrm{mg} / \mathrm{L}$ ) and contained the largest amounts of all of analyzed groups of compounds (hydroxycinnamic acids, anthocyanins and flavonols). The lowest concentrations of polyphenols were found in wines made from cranberries and bilberries (below $500 \mathrm{mg} / \mathrm{L}$ ). The dealcoholated berry wines were found to inhibit Bacillus cereus growth. Elderberry wines, despite their high content of polyphenols, did not show antimicrobial properties against the tested microorganisms. Antimicrobial properties may be affected by the combination and proportions of active compounds, and not only by the individual compounds. Our results show that berry fruit wines could provide biologically active compounds and at the same time protect against pathogens.

Supplementary Materials: The following are available online at http://www.mdpi.com/2304-8158/9/12/1783/s1, Figure S1: Chromatogram at $520 \mathrm{~nm}$ of bilberry wine obtained with HPLC-DAD; 3-Dp-gal; 4-Dp-glc; 5-Cy-gal; 6-Dp-ara; 7-Cy-glc; 8-Pt-gal; 9-Pt-glc; 10-Pn-gal;12-Pt-ara;13-Pn-glc; 14-Mv-gal; 15-Mv-glc; 16-Mv-ara. Figure S2: Chromatogram at $320 \mathrm{~nm}$ of bilberry wine obtained with HPLC-DAD; 7-CAH; 8-CA; 10-p-CoA; 18-p-CoA der. Figure S3: Chromatogram at $360 \mathrm{~nm}$ of bilberry wine obtained with HPLC-DAD; 11-M-glc; 14-Q-glc; 15-Q-metoxyhex; 18-K-gal; 19-K-glc; 21-M; 22-Q. Figure S4: Chromatogram at $520 \mathrm{~nm}$ of blackberry wine obtained with HPLC-DAD; 1-Cy-gal; 2-Cy-glc; 3-Cy-xyl; 5-Pg-glc; 7-Cy-3mal-glc; 8-Cy-6mal-glc; 9-Cy-dioxalyl glc. Figure S5: Chromatogram at $320 \mathrm{~nm}$ of blackberry wine obtained with HPLC-DAD; 11-CAH; 15-neoChA; 18-ChA; 21-pCoH. Figure S6: Chromatogram at $360 \mathrm{~nm}$ of blackberry wine obtained with HPLC-DAD; 23-Q-rut; 24-Q-gal; 25-Q-gluc; 26-Q-glc; 28-Qacetylhex; 29-Q-3[6" (3hydroxy-3 methyl-glut)] gal. Figure S7: Chromatogram at $520 \mathrm{~nm}$ of cranberry wine obtained with HPLC-DAD; 10-Cy-gal; 11-Cy-glc; 14-Cy-ara; 15-Pn-gal; 17-Pn-glc; 18-Pn-ara. Figure S8: Chromatogram at $320 \mathrm{~nm}$ of cranberry wine obtained with HPLC-DAD; 11-CAH; 12-ChA; 13-CA. Figure S9: Chromatogram at $360 \mathrm{~nm}$ of cranberry wine obtained with HPLC-DAD; 7-M-xyl; 9-M-ara; 14-Q-gal; 17-M-dimetoxy-hex; 18-Q-xyl; 19-Q-ara; 20-Q-rha; 21-M; 22-metoxyQ-xyl; 23-Q; 24-Q-benzoyl gal. Figure S10: Chromatogram at $520 \mathrm{~nm}$ of elderberry wine obtained with HPLC-DAD; 3-Cy-sam-5-glc; 4-Cy-sam; 5-Cy-glc. Figure S11: Chromatogram at $320 \mathrm{~nm}$ of elderberry wine obtained with HPLC-DAD; 7-neoChA; 13-CAH; 16-CA/ChA -coeluted; 23-p-CoA der; 32-ni $(\lambda \max =323)$. Figure S12: Chromatogram at $360 \mathrm{~nm}$ of elderberry wine obtained with HPLC-DAD; 17-Q-rut; 18-Q-glc;19-K-rut; 20-3-methylQ; 21-Q. Figure S13: Chromatogram at $520 \mathrm{~nm}$ of raspberry wine obtained with HPLC-DAD; 5-Cy-soph; 6-Cy-3(2glc) rut; 7-Pg-3glc-rut/Cy-glc. Figure S14: Chromatogram at $320 \mathrm{~nm}$ of raspberry wine obtained with HPLC-DAD; 12-CAH; 16, 17-pCoAHs; 18-CA. Figure S15 Chromatogram at $360 \mathrm{~nm}$ of raspberry wine obtained with HPLC-DAD; 14-Q-2gal-rha; 20-Q-rut; 21- Q-gluc; 22-K-gal; 23-K-gluc; 25-Q; 26-K. Figure S16: Chromatogram at $520 \mathrm{~nm}$ of strawberry wine obtained with HPLC-DAD; 7-Cy-gal; 12 Cy-glc; 15- Pg-glc; 16-Pg-rut; 17-Pg-3,5diglc; 18-Pg-3mal-glc; 22-Pg-3-acet-glc. Figure S17: Chromatogram at $320 \mathrm{~nm}$ of strawberry wine obtained with HPLC-DAD; 12-malonyloCQA; 19-p-CoH; 31-pCoA; 42-5-hydroxyF hex. Figure S18 Chromatogram at $360 \mathrm{~nm}$ of strawberry wine obtained with HPLC-DAD; 39-Q-gluc; 40-Q-glc; 41-K-gluc; 42-Q.

Author Contributions: Conceptualization, A.C. and A.W.; methodology, A.C., A.W., A.N.; investigation, A.C., A.W., A.S.; writing—original draft preparation, A.C.; writing—review and editing, A.C., A.N. All authors have read and agreed to the published version of the manuscript.

Funding: This research received no external funding.

Conflicts of Interest: The authors declare no conflict of interest.

\section{References}

1. Čakar, U.; Petrović, A.; Pejin, B.; Čakar, M.; Živković, M.; Vajs, V.; Đorđević, B. Fruit as a substrate for a wine: A case study of selected berry and drupe fruit wines. Sci. Hortic. 2019, 244, 42-49. [CrossRef]

2. Czyżowska, A.; Pogorzelski, E. Changes to polyphenols in the process of production of musts and wines from blackcurrants and cherries. Part I. Total polyphenols and phenolic acids. Eur. Food Res. Technol. 2002, 214, 148-154. [CrossRef]

3. Czyżowska, A.; Pogorzelski, E. Changes to polyphenols in the process of production of musts and wines from blackcurrants and cherries. Part II. Anthocyanins and flavanols. Eur. Food Res. Technol. 2004, 218, 355-359. [CrossRef] 
4. Czyżowska, A.; Klewicka, E.; Pogorzelski, E.; Nowak, A. Polyphenols, vitamin C and antioxidant activity in wines from Rosa canina L. and Rosa rugosa Thunb. J. Food Compos. Anal. 2015, 39, 62-68. [CrossRef]

5. Heinonen, M.I.; Lehtonen, P.J.; Hopia, A.I. Antioxidant activity of berry and fruit wines and liquors. J. Agric. Food Chem. 1998, 46, 25-31. [CrossRef]

6. Rupasinghe, H.P.V.; Clegg, S. Total antioxidant capacity, total phenolic content, mineral elements, and histamine concentrations in wines of different fruit sources. J. Food Compos. Anal. 2007, 20, 133-137. [CrossRef]

7. Schmitzer, V.; Veberic, R.; Slatnar, A.; Stampar, F. Elderberry (Sambucus nigra) wine. A product rich in health promoting compounds. J. Agric. Food Chem. 2010, 58, 10143-10146. [CrossRef]

8. Vuorinen, H.; Maatta, K.; Torronen, R. Content of flavonols myricetin, quercetin, and kaempferol in Finnish berry wines. J. Agric. Food Chem. 2000, 48, 2675-2680. [CrossRef]

9. Wilkowska, A.; Czyżowska, A.; Ambroziak, A.; Adamiec, J. Structural, physicochemical and biological properties of spray-dried wine powders. Food Chem. 2017, 228, 77-84. [CrossRef]

10. Behrends, A.; Weber, F. Influence of different fermentation strategies on the phenolic profile of bilberry wine (Vaccinium myrtillus L.). J. Agric. Food Chem. 2017, 65, 7483-7490. [CrossRef]

11. Hornedo-Ortega, R.; Álvarez-Fernández, M.A.; Cerezo, A.B.; Garcia-Garcia, I.; Troncoso, A.M.; Garcia-Parrilla, M.C. Influence of fermentation process on the anthocyanin composition of wine and vinegar elaborated from strawberry. J. Food Sci. 2017, 82, 364-372. [CrossRef]

12. Liu, S.; Marsol-Vall, A.; Laaksonen, O.; Kortesniemi, M.; Yang, B. Characterization and quantification of nonanthocyanin phenolic compounds in white and blue bilberry (Vaccinium myrtillus) juices and wines using UHPLC-DAD-ESI-QTOF-MS and UHPLC-DAD. J. Agric. Food Chem. 2020, 68, 7734-7744. [CrossRef]

13. Papadopoulou, C.; Soulti, K.; Roussis, I.G. Potential antimicrobial activity of red and white wine. Phenolic Extracts against strains of Staphylococcus aureus, Escherichia coli and Candida albicans. Food Technol. Biotechnol. 2005, 43, 41-46.

14. Sohn, H.-Y.; Son, K.H.; Kwon, C.-S.; Kwon, G.-S.; Kang, S.S. Antimicrobial and cytotoxic activity of 18 prenylated flavonoids isolated from medicinal plants: Morus alba L., Morus mongolica Schneider, Broussnetia papyrifera (L.) Vent, Sophora flavescens Ait and Echinosophora koreensis Nakai. Phytomedicine 2004, 11, 666-672. [CrossRef] [PubMed]

15. Xiao, Z.T.; Zhu, Q.; Zhang, H.Y. Identifying antibacterial targets of flavonoids by comparative genomics and molecular modeling. Open J. Genom. 2014, 3. [CrossRef]

16. Lee, Y.L.; Cesario, T.; Wang, Y.; Shanbrom, E.; Thrupp, L. Antibacterial activity of vegetables and juices. Nutrition 2003, 19, 994-996. [CrossRef] [PubMed]

17. Selma, M.V.; Espin, J.C.; Tomas-Barberan, F.A. Interaction between phenolics and gut microbiota: Role in human health. J. Agric. Food Chem. 2009, 57, 6485-6501. [CrossRef] [PubMed]

18. Clifford, M.; Scalbert, A. Review: Ellagitannins nature, occurence and dietary burden. J. Sci. Food Agric. 2000, 80, 1118-1125. [CrossRef]

19. Cushnie, T.; Lamb, A.J. Antimicrobial activity of flavonoids. Int. J. Antimicrob. Agents 2005, 26, 343-356. [CrossRef] [PubMed]

20. Nohynek, L.J.; Alakomi, H.L.; Kahkonen, M.P.; Heinonen, M.; Helander, I.M.; Oksman-Caldentey, K.M.; Puupponen-Pimiä, R.H. Berry phenolics: Antimicrobial properties and mechanisms of action against severe human pathogens. Nutr. Cancer 2006, 54, 18-32. [CrossRef]

21. Puupponen-Pimia, R.; Nohynek, L.; Hartmann-Schmidlin, S.; Kahkonen, M.; Heinonen, M.; Maatta-Riihinen, K.; Oksman-Caldentey, K.M. Berry phenolics selectively inhibit the growth of intestinal pathogens. J. Appl. Microbiol. 2005, 98, 991-1000. [CrossRef] [PubMed]

22. Krisch, J.; Galgoczy, L.; Tolgyesi, M.; Papp, T.; Vagvolgyi, C. Effect of fruit juices and pomace extracts on the growth of Gram-positive and Gram-negative bacteria. Acta Biol. Szeged. 2008, 52, 267-270.

23. Nile, S.H.; Park, S.W. Edible berries: Bioactive components and their effect on human health. Nutrition 2014, 30, 134-144. [CrossRef] [PubMed]

24. Morrissey, P.A.; Hill, T.R. Vitamins: Vitamin C. In Encyclopedia of Dairy Sciences, 2nd ed.; Elsevier, Academic Press: San Diego, CA, USA, 2011; pp. 667-674.

25. Czyzowska, A. Vitamin C. In Reference Module in Food Sciences; Elsevier: Amsterdam, The Netherlands, 2015; pp. 1-8. [CrossRef] 
26. Velić, D.; Amidžić Klarić, D.; Velić, N.; Klarić, I.; Petravić Tominac, V.; Mornar, A. Chemical Constituents of Fruit Wines as Descriptors of their Nutritional, Sensorial and Health-Related Properties. In Descriptive Food Science; InTechOpen: London, UK, 2018; Chapter 4. [CrossRef]

27. Rajkowska, K.; Otlewska, A.; Kunicka-Styczyńska, A.; Krajewska, A. Candida albicans impairments induced by peppermint and clove oils at sub-inhibitory concentrations. Int. J. Mol. Sci. 2017, 18, 1307. [CrossRef]

28. Dewhirst, F.E.; Chen, T.; Izard, J.; Paster, B.J.; Tanner, A.C.R.; Yu, W.-H.; Lakshmanan, A.; Wade, W.G. The Human Oral Microbiome. J. Bacteriol. 2010, 192, 5002-5017. [CrossRef]

29. EHOMD Expanded Human Oral Microbiome Database. Available online: http://www.homd.org/?name= HOMD\&taxonomy_level=1 (accessed on 20 November 2020).

30. Thiyahuddin, N.M.; Lamping, E.; Rich, A.M.; Cannon, R.D. Yeast Species in the Oral Cavities of Older People: A Comparison between People Living in Their Own Homes and Those in Rest Homes. J. Fungi 2019, 5, 30. [CrossRef]

31. Simões-Silva, L.; Ferreira, S.; Santos-Araujo, C.; Tabaio, M.; Pestana, M.; Soares-Silva, I.; Sampaio-Maia, B. Oral Colonization of Staphylococcus Species in a Peritoneal Dialysis Population: A Possible Reservoir for PD-Related Infections? Can. J. Infect. Dis. Med. Microbiol. 2018, 5789094. [CrossRef]

32. Bottone, E.J. Bacillus cereus, a volatile human pathogen. Clin. Microbiol. Rev. 2010, 23, 382-398. [CrossRef]

33. Czyżowska, A.; Kucharska, A.Z.; Nowak, A.; Sokół-Łętowska, A.; Motyl, I.; Piórecki, N. Suitability of the probiotic lactic acid bacteria strains as the starter cultures in unripe cornelian cherry (Cornus mas L.) fermentation. J. Food Sci. Technol. 2017, 54, 2936-2946. [CrossRef]

34. Rivero-Pérez, M.D.; González-Sanjosé, M.L.; Muńiz, P.; Pérez-Magarińo, S. Antioxidant profile of red-single variety wines microoxygenated before malolactic fermentation. Food Chem. 2008, 111, 1004-1011. [CrossRef]

35. Fogliano, V.; Verde, V.; Randazzo, G.; Ritieni, A. Method for measuring antioxidant activity and its application to monitoring antioxidant capacity of wines. J. Agric. Food Chem. 1999, 47, 1035-1040. [CrossRef]

36. Efenberger-Szmechtyk, M.; Nowak, A.; Czyżowska, A.; Kucharska, A.Z.; Fecka, I. Composition and Antibacterial Activity of Aronia melanocarpa (Michx.) Elliot, Cornus mas L. and Chaenomeles superba Lindl. Leaf Extracts. Molecules 2020, 25, 2011. [CrossRef]

37. Duarte, W.F.; Dias, D.R.; Oliveira, J.M.; Vilanova, M.; Teixeira, J.A.; Silva, J.B.D.A.E.; Schwan, R.F. Raspberry (Rubus idaeus L.) wine: Yeast selection, sensory evaluation and instrumental analysis of volatile and other compounds. Food Res. Int. 2010, 43, 2303-2314. [CrossRef]

38. Duarte, W.F.; Dragone, G.; Dias, D.R.; Oliveira, J.M.; Teixeira, J.A.; Silva, J.B.D.A.E.; Schwan, R.F. Fermentative behaviour of Saccharomyces strains during microvinification of raspberry juice (Rubus idaeus L.). Int. J. Food Microbiol. 2010, 143, 173-182. [CrossRef] [PubMed]

39. Veberic, R.; Jakopic, J.; Stampar, F.; Schmitzer, V. European elderberry (Sambucus nigra L.) rich in sugars, organic acids, anthocyanins and selected polyphenols. Food Chem. 2009, 114, 511-515. [CrossRef]

40. Johnson, M.H.; Mejia, E.G. Comparison of chemical composition and antioxidant capacity of commercially available blueberry and blackberry wines in Illinois. J. Food Sci. 2012, 77, C141-C148. [CrossRef]

41. Kalkan Yildirim, H. Evaluation of colour parameters and antioxidant activities of fruit wines. Int. J. Food Sci. Nutr. 2006, 57, 47-63. [CrossRef]

42. Ortiz, J.; Marin-Arroyo, M.-R.; Noriega-Dominguez, M.-J.; Navarro, M.; Arozarena, I. Color, phenolics, and antioxidant activity of blackberry (Rubus glaucus Benth.), blueberry (Vaccinium floribundum Kunth.), and apple wines from Ecuador. J. Food Sci. 2013, 78, C985-C993. [CrossRef]

43. Ljevar, A.; Curko, N.; Tomasevic, M.; Radosevic, K.; Gaurina Srcek, V.; Kovacevic Ganic, K. Phenolic composition, antioxidant capacity and in vitro cytotoxicity of fruit wines. Food Technol. Botechnol. 2016, 54, 145-155. [CrossRef]

44. Mudnic, I.; Budimir, D.; Modun, D.; Gunjaca, G.; Generalic, I.; Skroza, D.; Katalinic, V.; Ljubenkov, I.; Boban, M. Antioxidant and vasodilatory effects of blackberry and grape wines. J. Med. Food 2012, 15, 315-321. [CrossRef]

45. Mitic, M.N.; Obradovic, M.V.; Mitic, S.S.; Pavlovic, A.N.; Pavlovic, J.L.J.; Stojanovic, B.T. Free radical scavenging activity and phenolic profile of selected Serbian red fruit wines. Rev. Chim. 2013, 64, 68-73. 
46. Arozarena, I.; Ortiz, J.; Hermosín-Gutiérrez, I.; Urretavizcaya, I.; Salvatierra, S.; Córdova, I.; Marín-Arroyo, M.R.; Noriega, M.J.; Navarro, M. Color, ellagitannins, anthocyanins, and antioxidant activity of andean blackberry (Rubus glaucus Benth.) wines. J. Agric. Food Chem. 2012, 60, 7463-7473. [CrossRef]

47. Gao, X.; Björk, L.; Trajkovski, V.; Uggla, M. Evaluation of antioxidant activities of rosehip ethanol extracts in different test systems. J. Sci. Food Agric. 2000, 80, 2021-2027. [CrossRef]

48. Brand-Williams, W.; Cuvelier, M.E.; Berset, C. Use of a free radical method to evaluate antioxidant activity. LWT-Food Sci. Technol. 1995, 28, 25-30. [CrossRef]

49. Lingua, M.S.; Fabani, M.P.; Wunderlin, D.A.; Baroni, M.V. From grape to wine: Changes in phenolic composition and its influence on antioxidant activity. Food Chem. 2016, 208, 228-238. [CrossRef]

50. Rupasinghe, H.V.; Joshi, V.; Smith, A.; Parmar, I. Chapter 3-Chemistry of Fruit Wines. In Panesar, Science and Technology of Fruit Wine Production; Maria, R., Kosseva, V.K., Joshi, P.S., Eds.; Academic Press: Cambridge, MA, USA, 2017; pp. 105-176. ISBN 9780128008508. [CrossRef]

51. Ginjom, I.; D’Arcy, B.; Caffin, N.; Gidley, M. Phenolic compound profiles in selected Queensland red wines at all stages of wine-making process. Food Chem. 2011, 125, 823-834. [CrossRef]

52. Cerezo, A.B.; Cuevas, E.; Winterhalter, P.; Garcia-Parrilla, M.C.; Troncoso, A.M. Isolation, identification, and antioxidant activity of anthocyanin compounds in Camarosa strawberry. Food Chem. 2010, 123, 574-582. [CrossRef]

53. Hornedo-Ortega, R.; Krisa, S.; Garcia-Parrilla, M.C.; Richard, T. Effect of gluconic and alcoholic fermentation on anthocyanin composition and antioxidant activity of beverages made from strawberry. LWT-Food Sci. Technol. 2016, 69, 382-389. [CrossRef]

54. Olejnik, A.; Olkowicz, M.; Kowalska, K.; Rychlik, J.; Dembczyński, R.; Myszka, K.; Juzwa, W.; Białas, W.; Moyer, M.P. Gastrointestinal digested Sambucus nigra L. fruit extract protects in vitro cultured human colon cells against oxidative stress. Food Chem. 2016, 197, 648-657. [CrossRef]

55. Sellappan, S.; Akoh, C.C.; Krewer, G. Phenolic compounds and antioxidant capacity of Georgia grown blueberries and blackberries. J. Agric. Food Chem. 2002, 50, 2432-2438. [CrossRef]

56. Wu, X.; Prior, R.L. Systematic identification and characterization of anthocyanins by HPLC-ESI-MS/MS in common food in the United States: Fruits and berries. J. Agric. Food Chem. 2005, 53, 2589-2599. [CrossRef]

57. Fan-Chiang, H.J.; Wrolstad, R.E. Anthocyanin pigment composition of blackberries. J. Food Sci. 2005, 70, C198-C202. [CrossRef]

58. Bowen-Forbes, C.S.; Zhang, Y.; Nair, M.G. Anthocyanin content, antioxidant, antiinflammatory and anticancer properties of blackberry and raspberry fruits. J. Food Compos. Anal. 2010, 23, 554-560. [CrossRef]

59. Klopotek, Y.; Otto, K.; Böhm, V. Processing strawberries to different products alters contents of vitamin C, total phenolics, total anthocyanins, and antioxidant capacity. J. Agric. Food Chem. 2005, 53, 5640-5646. [CrossRef]

60. Ubeda, C.; Callejón, R.M.; Hidalgo, C.; Torija, M.J.; Troncoso, A.M.; Morales, M.L. Employment of different processes for the production of strawberry vinegars: Effects on antioxidant activity, total phenols and monomeric anthocyanins. LWT-Food Sci. Technol. 2013, 52, 139-145. [CrossRef]

61. Buchert, J.; Koponen, J.M.; Suutarinen, M.; Mustranta, A.; Lille, M.; Törrönen, R.; Poutanen, K. Effect of enzyme-aided pressing on anthocyanin yield and profiles in bilberry and blackcurrant juices. J. Sci. Food Agric. 2005, 85, 2548-2556. [CrossRef]

62. Nowicka, A.; Kucharska, A.Z.; Sokół-Łętowska, A.; Fecka, I. Comparison of polyphenol content and antioxidant capacity of strawberry fruit from 90 cultivars of Fragaria $\times$ ananassa Duch. Food Chem. 2019, 270, 32-46. [CrossRef] [PubMed]

63. Kylli, P.; Nohynek, L.; Puupponen-Pimia, R.; Westerlund-Wikstrom, B.; Leppanen, T.; Welling, J.; Moilanen, E.; Heinonen, M. Lingonberry (Vaccinium vitis-idaea) and European Cranberry (Vaccinium microcarpon) Proanthocyanidins: Isolation, Identification, and Bioactivities. J. Agric. Food Chem. 2011, 59, 3373-3384. [CrossRef] 
64. Puupponen-Pimia, R.; Nohynek, L.; Meier, C.; Kahkonen, M.; Heinonen, M.; Hopia, A.; Oksman-Caldentey, K.M. Antimicrobial properties of phenolic compounds from berries. J. Appl. Microbiol. 2001, 90, 494-507. [CrossRef]

Publisher's Note: MDPI stays neutral with regard to jurisdictional claims in published maps and institutional affiliations.

(C) 2020 by the authors. Licensee MDPI, Basel, Switzerland. This article is an open access article distributed under the terms and conditions of the Creative Commons Attribution (CC BY) license (http://creativecommons.org/licenses/by/4.0/). 